\title{
Polycentric systems as one approach for solving collective- action problems
}

\author{
Elinor Ostrom ${ }^{1}$ \\ (C) 2008 by author
}

Providing and producing public goods and common-pool resources at local, regional, national and international levels require different institutions than open, competitive markets or highly centralized governmental institutions. If we are to solve collectiveaction problems effectively we must rethink the way we approach market and governmental institutions. We need analytical approaches that are consistent with a public sector that encourages human development at multiple levels (Opschoor 2004). This chapter reviews studies of polycentric governance systems in metropolitan areas and for managing common-pool resources.

Hans Opschoor has devoted his academic career to the study of economic instruments and institutions related to development of and to coping with environmental problems. A fundamental set of problems facing individuals in all developed and developing societies are collective-action problems. The size and shape of these problems however differ dramatically. Polycentricity may help solve collective-action problems by developing systems of governmental and nongovernmental organizations at multiple scales.

After an introduction to the problem, this chapter will review the extensive research that demonstrated the capabilities of many citizens to design imaginative and productive ways of producing public goods and common-pool resources. Successful systems tend to be polycentric with small units nested in larger systems. Not all such systems are successful, and we need to understand factors associated with failure as well as success. The last section of the chapter will discuss design principles that can help guide the design, adaptation and reform of governance systems to achieve robust and effective systems over time.

\section{Matching scales of governance systems to solve collective-action problems}

Collective-action problems occur when it takes the inputs and efforts of multiple individuals in order to achieve joint outcomes - and it is difficult to exclude beneficiaries of these actions from benefiting even if they do not contribute (E. Ostrom 1998). Collective-action problems vary in scale from very small problems involving only a few individuals to extremely large problems involving global resources, such as the atmosphere and the oceans. Solving collective-action problems requires opening public and private spheres of activities ranging from the small to the very large so as to encourage effective problem solving (Hess and Ostrom 2007). 
Regarding the provision and production of private goods-goods that are relatively easy to package and lack major externalities - creating open, competitive markets is conducive to increased levels of investment, innovation, and lower prices to consumers.

Entrepreneurship plays a key role in the private sector since entrepreneurs are the ones who must discover strategies to put heterogeneous factors of production together in new and complementary ways given the availability of resources and technology. In the private sector the profit motive is the driving force for private entrepreneurs.

Providing and producing public goods and common-pool resources-including public safety; conflict resolution at international, national, regional and local levels; public education; and public health, as well as sustaining natural resource systems-require different institutions than an open, competitive market. Even the market itself is not a viable, independent institution without the presence of effective public property arrangements, courts of law and police (Opschoor et al. 1999).

The language used by many analysts divides the rich world of institutions into a barren dichotomy of the market versus the state. While most consider markets to be open, public realms where many individuals and firms of diverse sizes and assets compete, the depiction of the public sector is as a top down hierarchy with little room for problem solving except by top level, government officials. Whether a system is federal or not, some scholars prefer to think about governance occurring primarily at the national level. Even federal countries may need to think about expanding some of their problem solving capabilities to an international level with respect to specific functions larger than any units within their federal systems thus far (Frey 2005).

If we are to solve collective-action problems effectively, we must rethink the way we approach market and governmental institutions (E. Ostrom 2006, 2007). Analytical approaches that are consistent with a public sector that encourages human development at local, regional, national, and international levels is required (Opschoor 2004). Diverse interests motivate public entrepreneurs including improving services to their own communities, sharing the burden for increasing benefits, the stimulus of innovation, the respect they receive from others, as well as the income they derive from their positions in public service for those who are not entirely volunteer workers (Mintrom 2000; Kuhnert 2001).

Extensive studies of urban service delivery (for overview see McGinnis 1999b) and of common-pool resources (E. Ostrom, Gardner, and Walker 1994; Gibson, McKean, and Ostrom 2000) conducted in association with the Workshop in Political Theory and Policy Analysis at Indiana University, found numerous communities in both urban and rural areas who have self organized to provide and coproduce quality local services, given the constraints that they face. Many policy analysts presume that without major external resources and top down planning by national officials, there can be no provision of public goods and sustainable common-pool resources. This presumption is wrong.

The opposite prescription that local communities will always solve collective-action problems is also wrong. It is a struggle to find effective ways of providing these services, 
but public entrepreneurs working closely with citizens frequently do find new ways of putting services together using a mixture of local talent and resources (Dietz, Ostrom, and Stern 2003). If governance systems arrange polycentrically, from small to very large, collective-action problems are solvable on multiple scales. The costs of effective self organization are lower when authority exists to create institutions whose boundaries match the problems faced. External financial resources may increase the options available to a local community. External resources are not the essential ingredient for building an effective public sector to provide local public goods and protect smaller scale commonpool resources. The results achieved have been grossly disappointing, for example solving local problems with the allocation of massive amounts of donor funds (Gibson et al. 2005).

The presumption that locals cannot take care of public sector problems has led to legislation throughout the world that places responsibility for local public services on units of government that are very large, frequently lack the resources to carry out and are overwhelmed with their assignment. Contemporary assignments of regional, national, or international governments with exclusive responsibility for providing local public goods and common-pool resources removes authority from local officials and citizens to solve local problems that differ from one location to the next. Doug Wilson, Research Director for the Institute for Fisheries Management and Coastal Community Development in Denmark, has recently reflected on the evolution of fisheries policies in the European Union.

The Common Fisheries Policy (CFP) as it is called is an exclusive competence of the European Union (EU) meaning that all decisions are taken at the level of the Union.... The CFP is not only politically important within the overall effort to build a new kind of polity in Europe; it is also failing to do a very good job of maintaining sustainable fish stocks. Fisheries scientists tell us that, in 2003, 22\% of the fish caught from stocks managed by the CFP came from stocks that were smaller than they should have been for sustainable fishing. Scientists, fishers, government agencies and marine conservation groups are all unhappy with the CFP, and there are myriad attempts to reform it. The reforms include better policy, better data gathering, a reduction in perverse subsidies to the fishing industry and, finally 30 years after most other fisheries management agencies had moved beyond top-down management, some serious attempts at stakeholder involvement (Wilson 2006, p. 7).

This emphasis on top down planning is certainly not the way Europe developed. Since the 11th century, in the Rhine River delta, thousands of independent water boards with their own rules and physical structures, drained the swampy land and protected the land from flooding except during extreme storms (Toonen 1996; Andersen 2001). In Switzerland, alpine peasants devised a variety of private and common property systems to gain profitable income from an extreme and diverse ecology (Netting 1981). More than 1000 free cities with their own charters and legal traditions flourished in Europe during the Middle Ages and were the foundation for modern constitutional democracies (Berman 1983). Drawing on the rich tradition of European public sector development, we 
need to think of the public sector as a polycentric system (V. Ostrom 1999) rather than a monocentric hierarchy.

Research has repeatedly demonstrated that order and high performance are more likely to be achieved in effective, local public economies established within broader national systems where large, medium, and small governmental and nongovernmental enterprises engage in diverse cooperative as well as competitive relationships (see Frey and Eichenberger 1996). Local public economies are not markets, nor are they simple hierarchies. Households in a local public economy are not able to engage in a wide diversity of independent quid pro quo relationships with any producer they choose. Decisions are made for collective consumption units-including a wide diversity of self organized associations as well as governments at multiple levels - that are then held responsible to provide tax revenue and user charges to pay for the provision of public goods and services. Local organizations also enhance the level of citizen coproduction of public safety, education and health. Entities in a public economy engage in extensive horizontal as well as vertical interrelationships. The structure and performance of a public economy at an interorganizational level as well as at the level of a single unit requires examination. We have repeatedly found that polycentric public economies outperform highly centralized ones (McGinnis 1999a, 1999b, 2000).

\section{Polycentric public economies in urban areas}

The basic assumptions of a polycentric theory, when applied to the study of urban areas, are:

1. Public goods and services differ substantially regarding their production functions and their scale of effects.

2. Individuals with relatively similar preferences for public goods and services tend to cluster in neighbourhoods. Preferences will tend to be more homogeneous within neighbourhoods than across an entire metropolitan area.

3. Citizens who live in multiple jurisdictions learn more about the performance of any one jurisdiction by seeing or hearing about how other jurisdictions handle problems.

4. Multiple jurisdictions with different scopes and scales of organization allow citizens more effective choice in selecting packages of services most important to them, in articulating their preferences and concerns, and if necessary, in moving to other jurisdictions.

5. The presence of large numbers of potential producers of urban goods and services in a metropolitan area allow elected officials more effective producer choices.

6. Producers who must compete for contracts are more likely to search for innovative technologies, to encourage effective team production, as well as citizen coproduction, to enhance their own performance (V. Ostrom 2008a, 2008b; E. Ostrom, Parks, and Whitaker 1978).

This modified form of competition - of vying for citizens to resolve problems and procure services in an urban neighbourhood-is one method for reducing opportunistic 
behaviour even though no institutional arrangement can eliminate opportunism with respect to the provision and production of collective goods. Allowing citizens to form neighbourhood level collective consumption units encourages face-to-face discussion and the achievement of common understanding. Creating larger collective consumption units reduces the strategic behaviour of the wealthy trying to escape into tax havens where they gain a free ride on the tax contributions of citizens in other jurisdictions. Larger units also can cope more effectively with urban goods and services that have large scale effects.

\section{Police in US metropolitan areas}

To illustrate the polycentric approach I will provide a short overview of our extensive research conducted in US metropolitan areas. The findings from our research are broadly relevant to urban areas of developed and developing countries elsewhere. Regarding the study of local economies in developing countries, colleagues associated with the Consortium for Self-Governance in Africa (CSGA) are currently studying the almost invisible, self organized systems that many citizens in Africa have devised given the lack of public goods produced by formal governments (Sawyer 2006).

During the 1970s and 1980s in response to concerns about police effectiveness in the face of increasing crime rates, proposals to slash the number of police departments serving urban and rural areas of the United States gained prominence on the national agenda. Underlying these proposals was the assumption that bigger is always better. Some proposals recommended reducing the more than 40000 police departments that then existed in the United States to less than 500 police departments for the entire country. No systematic empirical evidence supported these reform proposals.

\section{Small and medium sized police agencies are more effective at producing direct services}

Let me first report on a series of studies that measured the performance of diversely sized police agencies serving similar communities in the Indianapolis, Indiana; Chicago, Illinois; St. Louis, Missouri; Rochester, New York; and Tampa-St. Petersburg, Florida metropolitan areas. Interviews with a random sample of households served by small, medium and large departments provided data for a police performance measurement. Information obtained was on victimization, willingness to call the police, speed of police response, amount of police follow up, satisfaction levels with police contacts, and general evaluations of the quality of policing in a neighbourhood. By studying matched neighbourhoods with similar service conditions, we controlled for many of the other factors expected to affect performance.

The consistent finding from this series of studies was that small to medium sized police departments perform more effectively and frequently at lower costs than large police departments serving similar neighbourhoods (see McGinnis 1999b). Victimization rates tend to be lower, police response tends to be faster, citizens tend to be more willing to call police, citizens tend to evaluate specific contacts with police more favourably and to rate police higher across multiple indicators. 
Small police agencies arrange for indirect services from large police agencies

In our major study of police organization in 80 metropolitan areas (E. Ostrom, Parks, and Whitaker 1978), 1159 direct service producers produced services directly for the residents in the areas. Most of these agencies produced general area patrol, traffic patrol, accident investigation and burglary investigation services. Regarding indirect services we found 70 per cent of the direct service producers also produced their own radio communications, but only a small proportion of any of the direct service producers produced the other indirect services such as crime labs or entry level training. In all 80 Standard Metropolitan Statistical Areas (SMSAs), indirect services were available to all direct service producers.

\section{Enhanced Police performance in metropolitan areas with larger numbers of police agencies}

In order to examine the effect of interorganizational arrangements on police performance, we relied on measures of performance such as the allocation of police personnel to onthe-street assignments and the relative efficiency of agencies in producing response capacity and solving crime. For each of the 80 metropolitan areas, we calculated the number of producers of each type of service (multiplicity) and the proportion of the population served by the largest producer of each type of service (dominance). Metropolitan areas with low scores in multiplicity and high scores in dominance come closest to approximating the consolidated model. Metropolitan areas with high scores in multiplicity and low scores in dominance come closest to approximating the fragmented metropolitan area model criticized by these same proponents.

We found a distinct difference in the availability of sworn officers to conduct patrols in the metropolitan areas depending upon the structure of interorganizational arrangements. While more officers per capita were in the most consolidated areas, a lower percentage of these officers were to patrol divisions in these SMSAs. One third more officers were required in the most consolidated SMSAs to place the same number of officers on patrol as compared to the least consolidated SMSAs. Citizens living in the most fragmented metropolitan areas received more police presence on the streets for their tax expenditures than did citizens living in the most consolidated areas (Parks 1985).

\section{There is no one best system for all local public economies}

In addition to the research on police, scholars have conducted rigorous empirical research challenging the presumptions that larger public school districts achieve higher performance (Hanushek 1986; Teske et al. 1993). That fragmentation of governments leads to higher costs (Dilorenzo 1983; Schneider 1986; Boyne 1992) and have provided further insights into the construction of local governments (Oakerson and Parks 1989; Stephens and Wikstrom 2000). As a result of extensive empirical and theoretical research, the presumed self evident truth that constructing one government for each metropolitan area is the best way to achieve efficiency and equity, has slowly been replaced with recognition that judging 'structure directly on the single criterion of 
uniformity contributes little to the advancement of research or reform'(Oakerson 1999, p. 117). Instead of a single best design that would have to cope with the wide variety of problems faced in different localities, a polycentric theory generates core principles that can be used in the design of effective local institutions when used by informed and interested citizens and public officials.

In his conclusion to an in-depth study of urban consolidation efforts in the United States and Canada during the last century, Andrew Sancton (2000, p. 167) reflected:

Municipalities are more than just providers of services. They are the democratic mechanisms through which territorially based communities of people govern themselves at a local level.... Those who would force municipalities to amalgamate with each other invariably claim that their motive is to make municipalities stronger. Such an approach-however well intentioned-erodes the foundations of our liberal democracies because it undermines the notion that there can be forms of self-government that exist outside the institutions of the central government.

Those scholars, public officials and citizens who are concerned with solving collectiveaction problems effectively, equitably and efficiently, recognize the importance of authorizing citizens to constitute their own local jurisdictions and associations using the knowledge and experience they have concerning the public problems they face.

\section{Polycentricity and common-pool resources}

Let us now examine local institutional arrangements for common-pool resources. Common-pool resources are systems that generate finite quantities of resource units so that one person's use does subtract from the quantity of resource units available to others (E. Ostrom, Gardner, and Walker 1994). The use of forests, pastures and irrigation systems are among the important types of common-pool resources present in most countries of the world. Most common-pool resources are sufficiently large that multiple actors can simultaneously use the resource system and efforts to exclude potential beneficiaries are costly. When the resource units (for example: water, fish, trees) are highly valued and many actors benefit from harvesting them for consumption, exchange, or as a factor in a production process, the harvests withdrawn by one individual are likely to create negative externalities for others.

The phenomenon known as, tragedy of the commons will occur in highly valued, openaccess commons where those involved and/or external authorities do not establish an effective governance regime. Scholars have regularly recommended that private property regimes be imposed on local users since it has been assumed that local fishermen, forest users and irrigators could not design their own systems. Clark (2006) has shown that simply imposing an Individual Transferable Quota (ITQ) on those fishing from a coastal fishery is not a sufficient solution to the challenging problem of achieving sustainable harvests. Instead of presuming that there is one ideal governance regime, it is important to recognize that a variety of regimes may achieve sustainability. Instead of focusing on 
whether a regime is a government, private property or community property regime, we need to look at the specifics of how a regime matches (or does not match) some of the ecological conditions prevalent in a region (Costanza et al. 2001).

A more general way of thinking about governance, regimes are as sets of rules that regulate one or more of the following:

1. Who is allowed to appropriate resource units;

2. The timing, quantity, location and technology of appropriation;

3. Who is obligated to contribute resources to provide or maintain the resource system itself;

4. How appropriation and obligation activities are monitored and enforced;

5. How conflicts over appropriation and obligation activities are to be resolved; and

6. How the rules affecting the above will change over time with changes in the performance of the resource system and the strategies of participants.

A self governed common-pool resource is one where actors, who are major users of the resource, are involved over time in making and adapting rules within collective choice arenas regarding the inclusion or exclusion of participants, appropriation strategies, obligations of participants, monitoring and sanctioning, and conflict resolution. Some extremely remote common-pool resources are entirely user governed. Thus would have been the case for Swiss alpine meadows for many centuries (Netting 1981). In most modern political economies however it is rare to find any resource systems governed entirely by participants without rules made by local, regional, national and international authorities also affecting key decisions (V. Ostrom 1997, 2008b). Thus in a self governed, polycentric system, participants make many, but not necessarily all, rules that affect the sustainability of the resource system and its use.

\section{Conventional theory of common-pool resources}

Since the important early studies of open access fisheries by Gordon (1954) and Scott (1955), and the much cited work of Hardin (1968), many theoretical studies by political economists have analysed simple common-pool resource systems using relatively similar assumptions. In such systems the assumption is that, the resource generates a highly predictable, finite supply of one type of resource unit (one species, for example) in each relevant period. Further the assumption is that users are homogeneous in terms of their assets, skills, discount rates, cultural views and that they are short term, profit maximizing actors who possess complete information. In this theory anyone can enter the resource and harvest resource units. Users gain property rights only to what they harvest, which they then sell in an open, competitive market. The open access condition is a given and it is assumed that those involved cannot make any effort to change it. Harvesters act independently and do not communicate or coordinate their activities in any way.

Many textbooks in resource economics and law present this conventional theory as the only theory needed to understand common-pool resources in general. Field research challenges the universality of this theory. 


\section{Common-pool resources in the field}

A sufficient number of empirical examples exist where the absence of property rights and the independence of actors capture the essence of the problem facing users, that until the mid 1980s field researchers had not challenged the broad empirical applicability of the conventional theory, effectively. Until the work of the National Academy of Sciences' Panel on Common Property (National Research Council 1986), the basic theory discussed above was applied to all common-pool resources regardless of the capacity of appropriators. The growing evidence from many field studies called for a serious rethinking of the theoretical foundations for the analysis of common-pool resources (see Berkes 1989; Berkes et al. 1989; Bromley et al. 1992; McCay and Acheson 1987). The consequence of these empirical studies is not to challenge the empirical validity of the conventional theory, where it is relevant but rather its generalness.

James Acheson, James Wilson, and colleagues (Acheson 2003; Acheson, Wilson, and Steneck 1998; Wilson et al. 1994; Wilson, Yan, and Wilson 2007) documented how the lobster fishermen of Maine recovered from a major crash of the lobster stock in their coastal waters during the 1920s and 1930s by experimenting with a diversity of ingenious rules well fitted to important attributes of the relevant resource units - the lobsters - and how fishermen were organized within the harbours where they lived and berthed their boats. The lobster fishermen of Maine have lived in shoreline communities for multiple generations and have deep roots in their communities. They have been able to organize locally and develop norms of trustworthiness and reciprocity. Given their long history, they have gained effective knowledge about their local resource system to build an ever more valuable local fishery-with sales of lobster from the State of Maine totalling \$186.1 million in 2000 (Acheson 2003, p. 13).

In the field many attributes different than those in the basic theory of an open access resource, presented in some textbooks, characterize common-pool resources. Local farmers often build small to medium sized irrigation systems and they develop complex governance systems that specify who can use the resource, when and how much water can be withdrawn, how rules will be monitored and when sanctions will be imposed. Thus irrigation systems are one setting in which to examine how diverse types of governance systems perform in the field (Tang 1992; Shivakoti and Ostrom 2001; Meinzen-Dick 2007).

Recent research on small to medium sized irrigation systems in Nepal has found a substantial difference in performance between those systems owned and governed by the farmers themselves and those systems owned and operated by a national governmental agency. Colleagues associated with the Asian Institute of Technology in Bangkok have been working with colleagues at Indiana University since the early 1990s (Benjamin et al. 1994; Lam, Lee, and Ostrom 1994) to develop an extensive database on the performance of irrigation systems in Nepal. 
Farmers in Nepal have long taken on the responsibility to create their own water associations, construct and maintain their own systems, and monitor and enforce conformance to their rules. The irrigation systems constructed and maintained by farmers tend to rely on low tech construction techniques including building nonpermanent head works from mud, trees and stones. International aid agencies have provided considerable funding to government agencies in an effort to upgrade engineering standards.

In a detailed analysis of data from 150 farmer governed and national government irrigation systems in Nepal, Lam (1998) developed three performance measures: (1) the physical condition of irrigation systems, (2) the quantity of water available to farmers at different seasons of the year, and (3) the agricultural productivity of the systems. Using multiple regression analysis techniques to control for environmental differences among systems, Lam finds several variables strongly related to these dependent variables. One is the form of governance of the system. Holding other variables constant, irrigation systems governed by the farmers themselves perform significantly better on all three performance measures. This variable has the largest explanatory power of any variable in Lam's analysis, including the physical size of the system, terrain characteristics and the number of farmers.

We have continued to develop the Nepal Irrigation Institutions and Systems (NIIS) database, which now has information on about 231 irrigation systems located in 29 of the 75 districts in Nepal (Joshi et al. 2000). ${ }^{2}$ Our consistent finding and that of other scholars doing research on irrigation in Nepal (Gautam, Agrawal, and Subedi 1992), backs up Lam's earlier study and finds that on average, farmer-managed irrigation systems (FMIS) outperform agency-managed irrigation systems (AMIS) on multiple dimensions. Below is a brief overview of our findings from the NIIS database. ${ }^{3}$

Focusing on three measurements of the physical condition of the irrigation system at the time of data collection, a larger proportion of FMIS is able to maintain the overall system in excellent or moderately good condition. As well as achieve higher technical and economic efficiency as contrasted with AMIS (see Lam 1998 for definitions of these concepts). The better physical condition of the canals enables FMIS to achieve increased levels of cropping intensity (the number of crops grown during a year) at both the head end of a canal and the tail end of the canal. Thus farmers' investment in keeping their systems in good physical condition pays off with significantly more agricultural productivity.

About two thirds of both FMIS and AMIS have formal written rules that include provisions for imposing fines on farmers for not contributing resources to operate and manage the systems (Joshi et al. 2000, p. 75). On the other hand eight out of ten AMIS hire an official guard, while only six out of ten FMIS rely on an official guard (ibid.). The presence of an official guard however does not translate into an increased likelihood of the imposition of fines. On 75 per cent of the FMIS, fines are actually imposed when farmers are observed to break a rule while fines are actually imposed on only 38 per cent of the AMIS (ibid. p. 76). Farmers follow the rules of their system more on FMIS than on AMIS and they tend to achieve a higher level of mutual trust (ibid.). 
The specific rules that the farmers use in governing their systems on a day to day basis vary substantially from one system to another since each FMIS has been self organized. The official guard on many of these systems is actually one of the farmers who rotate into this position on a regular basis. The rules specifying allocation, responsibilities for monitoring and punishment; however, are not consistent from one system to the next. Thus monitoring of water allocation and contributions to maintenance performed, almost exclusively, by farmers who have participated in the design of specific rules garnering their own system, have a strong interest in seeing their system perform well and ensure that others on the system are not taking more water than their official share.

Thus farmers with long term ownership claims, who can communicate, develop their own agreements, establish positions of monitors and sanction those who do not conform to their own rules, are more likely to grow more rice, distribute water more equitably and keep their systems in better repair than on government systems. While there is variance in the performance of these Nepali systems, few perform as poorly as government systems holding other relevant variables constant. Since many of the government systems rely on high tech engineering, the capability of farmers to increase agricultural production on their primitive systems, while providing the labour to maintain and operate the system, is particularly noteworthy. ${ }^{4}$

In the last decade we have been studying diversely organized institutions for managing forests around the world. Instead of one model that works well in all types of forests, we have found national government owned forests that work well and are associated with sustainable forests, and government forests that are rife with illegal harvesting and are unable to stop poachers (Dietz, Ostrom, and Stern 2003; E. Ostrom and Nagendra 2006). We found the same diverse patterns for community managed forests and privately owned forests. To sustain forests over time requires much more than simply imposing a particular blueprint on a forested area. The capacity and incentives of those in a forest governance organization have to fit the collective-action problems faced in sustaining forests over time (Moran and Ostrom 2005; Hayes and Ostrom 2005).

\section{Design principles rather than blueprints}

In my effort to speculate on why some locally developed regimes for regulating the use of common-pool resources survived for long periods and others failed (E. Ostrom 1990), I developed what I considered to be a set of design principles that underlay the robust, long lasting systems and were rarely observed in the systems that had failed. When I first wrote about these design principles, I was concerned that I was speculating based on reading a very large number of individual case studies and my own earlier empirical work. I urged others to test out these tentative conclusions through further empirical research that would help ascertain if these principles distinguished between robust and failed systems. Since publishing Governing the Commons, other scholars have responded to the challenge. As discussed below and in Ostrom (2005), many scholars have examined the relevance of these principles for helping to explain the performance of 
resource governance systems (such as fisheries, irrigation systems, pastures and forests) throughout the world. ${ }^{5}$

For example Weinstein (2000) examined indigenous inshore fishery institutions in Canada and Japan. He found that the design principles I had earlier proposed were largely what characterized these long lived institutions. Abernathy and Sally (2000) studied nine small, but long surviving, irrigation systems in the dry areas of Burkina Faso and Niger. They measured system performance using both physical and nonphysical factors and found that an average measure of performance based on six indicators was highly correlated with governance arrangements conforming to the design principles (see Crook and Jones 1999; Merrey 1996, who found supporting evidence). In light of positive support by other scholars for the validity of the design principles, let us briefly review some of the research that has focused specifically on these principles.

\section{Well defined boundaries}

The first design principle is to define the boundaries of the resource system clearly, as well as the individuals or households with rights to harvest resource units. If a group of users can determine their own membership-including those who agree to use the resource according to their agreed upon rules and excluding those who do not agree to these rules - the group has made an important first step toward limiting access and developing greater trust and reciprocity. Using this principle enables participants to know who is in and who is out of a defined set of relationships. Thus they know with whom to cooperate. Smaller resource governance systems do not always have extensively developed rule systems, but those that are robust do tend to always demark their boundaries (see Schlager 1994; Berkes 2007; Berkes et al. 2001).

Group boundaries frequently possess well understood attributes, such as residing in a particular community or joining a specific local cooperative. Membership may be marked by various tags (symbolic boundaries) and involve complex rituals and beliefs that help solidify individual beliefs about the trustworthiness of others. Contemporary developments in evolutionary theory applied to cultural systems and processes of adaptation help to explain how these design principles work to help groups sustain and build their cooperation over long periods.

Just the process of defining the boundaries carefully however may not be sufficient in and of itself. In his study of irrigation systems in Nepal, Shukla (2002) found that almost all of the systems he studied had well-demarked boundaries. A substantial difference existed between the FMIS discussed above as contrasted with the AMIS. On the FMIS the farmers themselves determine the size of the areas served. The farmers who demark the boundary will also have to participate in the construction of the system and its maintenance by contributing time, materials and potentially some funds. Thus the boundaries of irrigation systems developed by farmers tend to be conservative so that those who make the system work have more surety of getting water. 
By contrast the demarcation of boundaries in AMIS tends to take place through donor funded projects. Irrigation engineers are strongly motivated to show a positive benefitcost ratio. The more farmers placed within the service boundary of a system, the higher the benefits reported in the plans submitted to donors for funding. After initial funding few efforts to check the reliability of earlier estimates occur. In fact farmers in the larger service area are promised water, but may not receive a reliable supply. Moreover farmers on these systems are more likely to steal water and less likely to contribute resources to maintenance.

\section{Proportional equivalence between benefits and costs}

The second design principle is that the rules in use allocate benefits proportional to inputs that are required. Devising rules related to how much, when and how to harvest different products and how costs for operating a system are to be assessed is essential if a group of users wants to harvest from a resource over the long run. When the rules related to the distribution of benefits are consistent with the distribution of costs, participants are more willing to contribute to keep a resource well maintained and sustainable. Relating user inputs to the benefits they obtain is a crucial element of establishing a fair system (Trawick 2001). If some users get all the benefits and pay few of the costs, others will not be willing to follow rules over time (Ensminger 2000).

With different rules in place in long surviving irrigation systems, for assessing water fees used to pay for maintenance activities, water tends to be allocated proportional to monetary fees or required labour inputs (Bardhan 2000; Bardhan and Dayton-Johnson 2002). Sometimes distribution of water and responsibilities for resource inputs relate to the shares owned by farmers and sometimes to the amount of land owned and irrigated, and sometimes to the order in which water is taken (Tang 1992; Lam 1998).

\section{Collective choice arrangements}

The third design principle is that most of the individuals affected by a resource regime may participate in enacting their rules. This enables regimes to tailor rules to local circumstances and to devise rules considered fair by participants. As environments change over time, being able to construct local rules is particularly important, as officials located far away do not know of any changes. When local elite is empowered at the collective choice level, policies that primarily benefit them can be expected (Platteau 2003, 2004; Ensminger 1990).

In a study of 48 irrigation systems in India, Bardhan (2000) finds that the maintenance quality of irrigation canals is significantly lower on those systems where farmers perceive rules made by local elite. On the other hand those farmers (of the 480 interviewed) who responded that the rules for their system have been crafted by most of the farmers, as contrasted with the elite or the government, have a more positive attitude about water allocation rules and rule compliance of other farmers. In all of the villages where a government agency decides the allocation and distribution of water, farmers report frequent rule violations and tend to contribute less to the local village fund. 


\section{Monitoring}

Relying only on endogenous levels of trust and reciprocity among harvesters is not associated with long-term regime survival. Rule enforcement must occur in some manner to achieve sustainable systems. Too often the question of how rule enforcement will occur is ignored when a reform is proposed. All too many comanaged paper parks were drafted in the home office of an overseas donor or even in a country's capital city only to be destroyed by illegal harvesting in the specified territory. While many agree that rule enforcement is necessary to create a sustainable resource over time, considerable disagreement exists about who should monitor (see Bruner et al. 2001; Wells and Brandon 1992).

Most long surviving resource regimes do select their own monitors, who are accountable to the appropriators or are appropriators themselves and who keep an eye on resource conditions as well as on harvesting activities. By creating official positions for local monitors, a resource regime does not have to rely only on local community norms to sanction a rule breaker. The community creates an official position. In some systems users rotate into this position so everyone has monitor duty. In other systems all participants contribute resources and they jointly hire monitors.

In a study of the forest conditions used by 178 forest user groups located in 12 countries studied by the International Forestry Resources and Institutions (IFRI) research network, Gibson, Williams, and Ostrom (2005) found that the level of local monitoring varies substantially across groups. One of the measures obtained in this study is the frequency with which a local group monitors and sanctions rule breaking behaviour in the forest. ${ }^{6}$ We examined the impact of this variable on appropriators' assessment of forest conditions (as well as on a forester's assessment). We also examined the impact of group social capital, group dependence on forest resources and the degree of formal group organization. The result of the analysis is that regular monitoring by a local group is more important than the other three variables in enhancing forest conditions. Regardless of the levels of social capital, forest dependence, and formal organization, regular monitoring and sanctioning are strongly and statistically associated with better forest conditions.

\section{Graduated sanctions}

The fifth design principle is the use of graduated sanctions by robust governance arrangements. In many self organized systems the initial sanction imposed by a local monitor is small. The initial sanction needs to be considered more as information to the person who is caught as well as to others in the community. Everyone can make an error or can face difficult problems leading them to break a rule. In a regime that uses graduated punishments, a person who purposely or by error breaks a rule is notified that others noticed the infraction (thereby increasing confidence that others would also be caught). Further the individual learns that others continue to extend their trust and want only a small token to convey recognition that the mishap occurred. The capability to 
escalate sanctions enables a regime to warn members that if they do not conform they will have to pay higher sanctions.

\section{Conflict resolution mechanisms}

Operation of the above principles is bolstered by the sixth principle, which points to the importance of access to rapid, low cost, local arenas to resolve conflict among users or between users and officials. Rules unlike physical constraints, have to be understood in order to be effective. Situations always exist in which participants can interpret a rule differently. By devising simple mechanisms to get conflicts aired immediately and resolutions that are generally known in a community, the number of trust reducing conflicts can go down. If individuals are going to follow rules over a long period, they must institute some mechanism for discussing and resolving what is or is not a rule infraction.

\section{Minimal recognition of rights}

The seventh design principle affects the capability of local users to develop an effective regime over time. While some resource regimes have operated for relatively long periods without such rights (see Ghate 2000), participants have had to rely almost entirely on unanimity as the dictate used to change rules. Otherwise any temporarily disgruntled participant who voted against a rule change could go to external authorities to threaten the regime itself. Unanimity in order to change rules imposes high transaction costs and prevents a group from searching for better rules at relatively lower costs.

Some users do devise their own rules without creating formal, governmental jurisdictions for this purpose. In many inshore fisheries for example, local fishers devise extensive rules defining who can use a fishing ground and what kind of equipment can be used (Schlager 2004). So long as external governmental officials give at least minimal recognition to the legitimacy of such rules, the fishers themselves may be effective enforcers of these rules when government agencies do not have the staff to enforce them. When external governmental officials presume that only they can make authoritative rules, then it is difficult but not impossible, for local users to sustain a self organized regime (Johnson and Libecap 1982).

\section{Nested enterprises}

When common-pool resources are larger, an eighth design principle tends to characterize robust systems - the presence of governance activities organized in multiple layers of nested enterprises. The rules appropriate for allocating water among major branches of an irrigation system for example, may not be appropriate for allocating water among farmers along a single distributory channel (Yoder 1994). Consequently among long enduring self governed regimes, smaller scale organizations tend to be nested in ever larger organizations. 


\section{Collective-action summary}

Thus our own and other scholars' consistent findings across empirical studies is that while there are general design principles, there are no magic formulae for solving collective-action problems. Collective-action problems come in a wide range of sizes and shapes. The design principles elucidated above are an effort to identify core principles rather than blueprints for how best to govern environmental goods and services, especially in federal systems of governance. Applying these principles to small and medium sized resource systems is a challenging task, but one that is simpler than designing effective institutions for global resources (E. Ostrom et al. 1999). The tough task ahead is to do the exacting empirical and theoretical work to identify which of these principles scales up to larger size and what new principles have to add.

\section{Bibliography}

Abernathy, Charles L. and Hilmy Sally (2000), 'Experiments of some governmentsponsored organizations of irrigators in Niger and Burkina Faso, West Africa', Journal of Applied Irrigation Studies, 35 (2), 177-205. Acheson, James (2003), Capturing the Commons: Devising Institution to Manage the Maine Lobster Industry, New Haven, CT: University Press of New England. Acheson, James, James Wilson, and Robert Steneck (1998), 'Managing chaotic fisheries', in Fikret Berkes and Carl Folke (eds.), Linking Social and Ecological Systems: Management Practices and Social Mechanisms for Building Resilience, Cambridge: Cambridge University Press, pp. 390-413. Andersen, M.S. (2001), Economic Instruments and Clean Water: Why Institutions and Policy Design Matters, Paris: OECD.

Araral, Eduardo (2005), 'Bureaucratic incentives, path dependence, and foreign aid: An empirical institutional analysis of irrigation in the Philippines', Policy Sciences 38 (2-3), September, 131-157.

Bardhan, Pranab K. (2000), 'Irrigation and cooperation: An empirical analysis of 48 irrigation communities in South India', Economic Development and Cultural Change, 48 (4), 847-865.

Bardhan, Pranab K. and Jeff Dayton-Johnson (2002), 'Unequal irrigators: Heterogeneity and commons management in large-scale multivariate research’, in National Research Council, Elinor Ostrom, Thomas Dietz, Nives Dolšak, Paul Stern, Susan Stonich, and Elke Weber (Committee on the Human Dimensions of Global Change) (eds.), The Drama of the Commons, Washington, DC: National Academy Press, pp. 87-112.

Benjamin, Paul, Wai Fung Lam, Elinor Ostrom, and Ganesh Shivakoti (1994), Institutions, Incentives, and Irrigation in Nepal, Decentralization: Finance and Management Project Report, Burlington, VT: Associates in Rural Development. Berkes, Fikret (ed.) (1989), Common Property Resources: Ecology and CommunityBased Sustainable Development, London: Belhaven Press. Berkes, Fikret (2007), 'Community-based conservation in a globalized world', Proceedings of the National Academy of Sciences, 104 (39), 15188-15193. Berkes, Fikret, David Feeny, Bonnie McCay, and James Acheson (1989), 'The benefits of the commons', Nature, 340 (6229), 91-93. 
Berkes, Fikret, Robin Mahon, Patrick McConney, Richard Pollnac, and Robert Pomeroy (2001), Managing Small-Scale Fisheries: Alternative Directions and Methods, Ottawa: International Development Research Centre. Berman, Harold J. (1983), Law and Revolution: The Formation of the Western Legal Tradition, Cambridge, MA: Harvard University Press.

Boyne, G. (1992), 'Local government structure and performance: Lessons from America’, Public Administration, 70, 333-357.

Bromley, Daniel, David Feeny, Margaret McKean, Pauline Peters, Jere Gilles, Ronald Oakerson, C. Ford Runge, and James Thomson (eds.) (1992), Making the Commons Work: Theory, Practice, and Policy, San Francisco, CA: ICS Press.

Bruner, Aaron, Raymond Gullison, Richard Rice, and Gustavo da Fonseca (2001), 'Effectiveness of parks in protecting tropical biodiversity', Science, 291 (5501), 125-129. Clark, Colin (2006), The Worldwide Crisis in Fisheries: Economic Models and Human Behavior, Cambridge: Cambridge University Press.

Costanza, Robert, Bobbi S. Low, Elinor Ostrom, and James Wilson (eds.) (2001), Institutions, Ecosystems, and Sustainability. New York: Lewis Publishers.

Crook, Darren S. and Anne M. Jones (1999), 'Design principles from traditional mountain irrigation systems (Bisses) in the Valais, Switzerland', Mountain Research and Development, 19 (2), 79-122.

Dietz, Thomas, Elinor Ostrom, and Paul Stern (2003), 'The struggle to govern the commons', Science, 302 (5652), 1907-1912; see also online supplement.

Dilorenzo, T. (1983), 'Economic competition and political competition: An empirical note', Public Choice, 40, 203-209.

Ensminger, Jean (1990), 'Co-opting the elders: The political economy of state incorporation in Africa', American Anthropologist, 92, 662-675.

Ensminger, Jean (2000), 'Experimental economics in the bush: Why institutions matter', in Claude Menard (ed.), Institutions, Contracts and Organizations, Cheltenham, UK: Edward Elgar, pp. 158-171.

Frey, Bruno S. (2005), 'Beyond traditional borders: A new proposal for federalism', The Economists’ Voice, 2 (2): article 9, http://www.bepress.com/ev/vol2/iss2/.

Frey, Bruno S. and Reiner Eichenberger (1996), 'FOCJ: Competitive governments for Europe', International Review of Law and Economics, 16 (3), 315-328.

Gautam, Upendra, Nanda Kishore Agrawal, and Rajan Subedi (eds.) (1992), Nepal:

Managing Large Surface Irrigation Project: A Participatory Review. Kathmandu, Nepal: Department of Irrigation and Consolidated Management Services. (Study Document NEP/89/006).

Ghate, Rucha (2000), 'The role of autonomy in self-organizing processes: A case study of local forest management in India', paper presented at the Workshop in Political Theory and Policy Analysis mini-conference, Bloomington, IN: Indiana University. Gibson, Clark, Krister Andersson, Elinor Ostrom, and Sujai Shivakumar (2005), The Samaritan's Dilemma: The Political Economy of Development Aid, New York: Oxford University Press.

Gibson, Clark, Margaret McKean, and Elinor Ostrom (eds.) (2000), People and Forests: Communities, Institutions, and Governance, Cambridge, MA: MIT Press.

Gibson, Clark, John Williams, and Elinor Ostrom (2005), 'Local enforcement and better forests', World Development, 33 (2), 273-284. 
Gordon, H. Scott (1954), 'The economic theory of a common property resource: The fishery’, Journal of Political Economy, 62, 124-142.

Hanushek, E.A. (1986), 'The economics of schooling: Production and efficiency in public schools', Journal of Economic Literature 24, 1141-1177.

Hardin, Garrett (1968), 'The tragedy of the commons', Science, 162, 1243-1248. Hayes, Tanya and Elinor Ostrom (2005), 'Conserving the world's forests: Are protected areas the only way?’, Indiana Law Review, 38 (3), 595-617.

Hess, Charlotte and Elinor Ostrom (eds.) (2007), Understanding Knowledge as a Commons: From Theory to Practice, Cambridge, MA: MIT Press.

Johnson, Ronald N. and Gary D. Libecap (1982), 'Contracting problems and regulation: The case of the fishery’, American Economic Review, 72 (5), 1005-1023.

Joshi, Neeraj, Elinor Ostrom, Ganesh Shivakoti, and Wai Fung Lam (2000), 'Institutional opportunities and constraints in the performance of farmer-managed irrigation systems in Nepal', Asia-Pacific Journal of Rural Development, 10 (2), 67-92.

Kuhnert, Stephan (2001), 'An evolutionary theory of collective action: Schumpeterian entrepreneurship for the common good', Constitutional Political Economy, 12, 13-29. Lam, Wai Fung (1998), Governing Irrigation Systems in Nepal: Institutions, Infrastructure, and Collective Action, Oakland, CA: ICS Press.

Lam, Wai Fung, Myungsuk Lee, and Elinor Ostrom (1994), 'An institutional analysis approach: Findings from the NIIS on irrigation performance', in Jennifer Sowerwine, Ganesh Shivakoti, Ujjwal Pradhan, Ashutosh Shukla, and Elinor Ostrom (eds.), From Farmers' Fields to Data Fields and Back: A Synthesis of Participatory Information Systems for Irrigation and Other Resources, Colombo, Sri Lanka: IIMI, and Rampur, Nepal: IAAS, pp. 69-93.

McCay, Bonnie and James Acheson (1987), The Question of the Commons: The Culture and Ecology of Communal Resources, Tucson: University of Arizona Press.

McGinnis, Michael (ed.) (1999a), Polycentric Governance and Development: Readings from the Workshop in Political Theory and Policy Analysis, Ann Arbor, MI: University of Michigan Press.

McGinnis, Michael (ed.) (1999b), Polycentricity and Local Public Economies: Readings from the Workshop in Political Theory and Policy Analysis, Ann Arbor, MI: University of Michigan Press.

McGinnis, Michael (ed.) (2000), Polycentric Games and Institutions: Readings from the Workshop in Political Theory and Policy Analysis, Ann Arbor, MI: University of Michigan Press.

Meinzen-Dick, Ruth (2007), 'Beyond panaceas in water institutions', Proceedings of the National Academy of Sciences, 104 (39), 15200-15205.

Merrey, Douglas J. (1996), 'Institutional design principles for accountability on large irrigation systems’, Research Report no. 8, Colombo, Sri Lanka: International Irrigation Management Institute.

Mintrom, Michael (2000), Policy Entrepreneurs and School Choice, Washington, DC: Georgetown University Press.

Moran, Emilio and Elinor Ostrom (eds.) (2005), Seeing the Forest and the Trees:

Human-Environment Interactions in Forest Ecosystems, Cambridge, MA: MIT Press. National Research Council (1986), Proceedings of the Conference on Common Property Resource Management, Washington, DC: National Academy Press. 
Netting, Robert McC. (1981), Balancing on an Alp: Change and Continuity in a Swiss Mountain Community, New York: Cambridge University Press.

Oakerson, Ronald (1999), Governing Local Public Economies: Creating the Civic Metropolis, Oakland, CA: ICS Press.

Oakerson, Ronald and Roger Parks (1989), 'Local government constitutions: A different view of metropolitan governance’, American Review of Public Administration, 19 (4), 279-284.

Opschoor, Johannes Baptist (2004), 'Knowledge sharing in support of human development', in Max Spoor (ed.), Globalization, Poverty and Conflict: A Critical Development Reader, Dordrecht: Kluwer Academic Press. 307-322.

Opschoor, Johannes Baptist, K. Button and P. Nijkamp (eds.) (1999), Environmental Economics and Development, Cheltenham, UK: Edward Elgar.

Ostrom, Elinor (1990), Governing the Commons: The Evolution of Institutions for Collective Action, New York: Cambridge University Press.

Ostrom, Elinor (1998), 'A behavioral approach to the rational choice theory of collective action’, American Political Science Review, 92 (1), 1-22.

Ostrom, Elinor (2005), Understanding Institutional Diversity, Princeton, NJ: Princeton University Press.

Ostrom, Elinor (2006), ‘Converting threats into opportunities’, PS: Political Science \& Politics, 39 (1), 3-12.

Ostrom, Elinor (2007), 'A diagnostic approach for going beyond panaceas', Proceedings of the National Academy of Sciences, 104 (39), 15181-15187.

Ostrom, Elinor, Joanna Burger, Christopher Field, Richard B. Norgaard, and David Policansky (1999), 'Revisiting the commons: Local lessons, global challenges', Science, 284 (5412), 278-282.

Ostrom, Elinor, Roy Gardner, and James Walker (1994), Rules, Games, and CommonPool Resources, Ann Arbor, MI: University of Michigan Press.

Ostrom, Elinor and Harini Nagendra (2006), 'Insights on linking forests, trees, and people from the air, on the ground, and in the laboratory', PNAS, 103 (51), 19224-19231. Ostrom, Elinor, Roger Parks, and Gordon Whitaker (1978), Patterns of Metropolitan Policing, Cambridge, MA: Ballinger.

Ostrom, Vincent (1997), The Meaning of Democracy and the Vulnerability of

Democracies: A Response to Tocqueville's Challenge, Ann Arbor, MI: University of Michigan Press.

Ostrom, Vincent (2008a), The Intellectual Crisis in American Public Administration. 3rd ed. Tuscaloosa: University of Alabama Press.

Ostrom, Vincent (2008b), The Political Theory of a Compound Republic: Designing the American Experiment. 3rd ed. Lanham, MD: Lexington Books.

Ostrom, Vincent (1999), 'Polycentricity', in Michael McGinnis (ed.), Polycentricity and Local Public Economies: Readings from the Workshop in Political Theory and Policy Analysis, Ann Arbor, MI: University of Michigan Press, pp. 52-74.

Parks, Roger (1985), 'Metropolitan structure and systemic performance: The case of police service delivery’, in Kenneth Hanf and Theo A.J. Toonen (eds.), Policy Implementation in Federal and Unitary Systems, Dordrecht, the Netherlands: Martinus Nijhoff, pp. 161-191. 
Platteau, Jean-Philippe (2003), 'Community based development in the context of within group heterogeneity', paper presented at the Annual Bank Conference on Development Economics, Bangalore, India.

Platteau, Jean-Philippe (2004), 'Monitoring elite capture in community-driven development', Development and Change, 35 (2), 223-246.

Sancton, Andrew (2000), The Assault on Local Government, Montreal: McGill-Queen's University Press.

Sawyer, Amos (2006), 'Social capital, survival strategies and their potential for postconflict governance in Liberia,' in Basudeb Guha-Khasnobis, Ravi Kanbur, and Elinor Ostrom (eds.), Linking the Formal and Informal Economy: Concepts and Policies, Oxford: Oxford University Press.

Schlager, Edella (1994), 'Fishers' institutional responses to common-pool resource dilemmas’, in Elinor Ostrom, Roy Gardner, and James Walker (eds.), Rules, Games, and Common-Pool Resources, Ann Arbor, MI: University of Michigan Press, pp. 247-265. Schlager, Edella (2004), 'Common-pool resource theory', in Robert Durant, Daniel Fiorino, and Rosemary O’Leary, Environmental Governance Reconsidered: Challenges, Choices, and Opportunities, Cambridge, MA: MIT Press, pp. 145-175.

Schneider, Mark (1986), 'Fragmentation and the growth of government', Public Choice, 48, 255-263.

Scott, Anthony (1955), 'The fishery: The objectives of sole ownership', Journal of Political Economy, 63, 116-124.

Shivakoti, Ganesh and Elinor Ostrom (2001), Improving Irrigation Governance and Management in Nepal, Oakland, CA: ICS Press.

Shukla, Ashutosh K. (2002), 'Policies, processes, and performance of management: Turnover and agency-initiated interventions', in Ganesh Shivakoti and Elinor Ostrom (eds.), Improving Irrigation Governance and Management in Nepal, Oakland: ICS Press, pp. 71-102.

Stephens, G.R. and N. Wikstrom (2000), Metropolitan Government and Governance: Theoretical Perspectives, Empirical Analysis, and the Future, New York: Oxford University Press.

Tang, Shui Yan (1992), Institutions and Collective Action: Self-Governance in Irrigation, San Francisco, CA: ICS Press.

Teske, Paul, Mark Schneider, Michael Mintrom, and Samuel Best (1993), 'Establishing the micro foundations of a macro theory: Information, movers, and the competitive local market for public goods’, American Political Science Review, 87 (3), 702-713.

Toonen, Theo A.J. (1996), 'On the administrative condition of politics: Administrative transformation in the Netherlands', West European Politics, 19 (3), 609-632.

Trawick, Paul B. (2001), 'Successfully governing the commons: Principles of social organization in an Andean irrigation system’, Human Ecology, 29 (1), 1-25.

Weinstein, Martin S. (2000), 'Pieces of the puzzle: Solutions for community-based fisheries management from native Canadians, Japanese cooperatives, and common property researchers', Georgetown International Environmental Law Review, 12 (2), 375412.

Wells, Michael and Katrina Brandon (1992), People and Parks: Linking Protected Area Management with Local Communities, Washington, DC: World Bank. 
Wilson, Doug (2006), 'Predictions about European commons', The Common Property Resource Digest, 77, 7-8.

Wilson, James, James Acheson, Mark Metcalfe, and Peter Kleban (1994), 'Chaos, complexity, and community management of fisheries’, Marine Policy, 18, 291-305.

Wilson, James, Liying Yan, and Carl Wilson (2007), 'The precursors of governance in the Maine lobster fishery', Proceedings of the National Academy of Sciences, 104 (39), 15212-15217.

Yoder, Robert (1994), Locally Managed Irrigation Systems, Colombo, Sri Lanka: International Irrigation Management Institute. 
${ }^{1}$ Elinor Ostrom is Arthur F. Bentley Professor of Political Science, Indiana University, Bloomington; co-Director, Workshop in Political Theory and Policy Analysis, Indiana University, Bloomington; Founding Director, Center for the Study of Institutional Diversity, Arizona State University, Tempe; and Professor (part-time), School of Public and Environmental Affairs, Indiana University, Bloomington. I am deeply appreciative of the support provided for my research in recent years by the National Science Foundation, Ford Foundation, and MacArthur Foundation. The brilliant editing and insights of Patty Lezotte have helped immensely with this manuscript and many others.

${ }^{2}$ Until recently, there has been considerable rebel activity in Nepal that disrupted many activities, creating many tragedies for Nepali farmers. The findings discussed in this chapter are based on data, most of which was collected in earlier peaceful times.

${ }^{3}$ Readers who wish to dig deeper are encouraged to read Lam (1998), Joshi et al. (2000), and Shivakoti and Ostrom (2001) and the extensive references cited therein.

${ }^{4}$ For an important study of Philippine irrigation systems with findings consistent with our findings in Nepal, see Araral (2005).

${ }^{5}$ This section draws on chapter 9 of E. Ostrom (2005).

${ }^{6}$ Four levels of monitoring were recorded: never, occasionally, seasonally, or year-round. We dichotomized this variable and recoded seasonal or year-round monitoring as regular and never or sporadic monitoring as sporadic. 